A Retrospective dataset on Climate Strike Twitter Hashtags

Sana Saeed", Yun Jin Kim², Linchao Qian², Muhammad Shahzad Aslam*

${ }^{1}$ Department of Computer science, Fast University, Lahore, Punjab 54000, Pakistan.

${ }^{* 2}$ School of Traditional Chinese Medicine, Xiamen University Malaysia, Sepang, 43900, Malaysia

*Corresponding Author:

Muhammad Shahzad Aslam, MPhil, PhD, PharmD

School of Traditional Chinese Medicine

Xiamen University Malaysia

Jalan Sunsuria, Bandar Sunsuria, Selangor

Sepang, 43900

Malaysia

Phone: 60387055209

Email: aslammuhammadshahzad@gmail.com; aslam.shahzad@xmu.edu.my 


\title{
A Retrospective dataset on Climate Strike Twitter Hashtags
}

\section{Sana Saeed ${ }^{1}$, Yun Jin Kim², Linchao Qian², Muhammad Shahzad Aslam ${ }^{2 *}$}

${ }^{1}$ Department of Computer science, Fast University, Lahore, Punjab 54000, Pakistan.

${ }^{* 2}$ School of Traditional Chinese Medicine, Xiamen University Malaysia, Sepang, 43900, Malaysia

\begin{abstract}
The climate change is a worldwide catastrophe and several fatal health issue such as stroke are increasing all around the world. A global strike has started on 15 march 2019 to raise an awareness on climate change. It was an international movement started from school students who skip classes to participate in demonstration to demand from leaders to stop climate disaster. The current study documented the data sets of \#climatestrike hashtags, from the twitter between $2^{\text {nd }}$ April 2019 till $30^{\text {th }}$ October 2020. The current dataset will helpful to determine the mobilizing information and characteristics of participants.
\end{abstract}

\section{Keywords}

Climate strike, Twitter, Hashtags, Retrospective dataset

\section{Introduction}

A catastrophic impact on human and environmental health may be caused by climate change. Higher rates of respiratory and heat-related diseases, increased prevalence of vector-borne and waterborne diseases, food and water shortages, and malnutrition are potential effects of climate change on human health (1). The increasing emergence of respiratory infections (i.e. coccidiodomycosis, avian influenza) (2) and heat stress nephropathy (3) is apparently due to global warming.

Early in 2018, young children and adolescents around the world took part in demonstration activities aimed at subsidiary government action on climate change. This activism was started and led by Greta Thunberg, a Swedish teenager. The School Strike 4 Atmosphere used social media, including other contemporary protests (4). Six million people have taken to the streets over the past week, uniting across time zones, cultures and generations to demand urgent action on the escalating ecological emergency (5). 
Twitter has rather evolved into a pool of constantly updating information streams consisting of links, short status updates, and eyewitness news (6). There are 330 million monthly active users and 145 million daily active users on Twitter (7). Twitter is an important medium to increase the health awareness campaign (8) and digital journalism (9). The objective of current study is to collect the data retrospectively from twitter on \#climatestrike

\section{Materials and methods}

Data was collected retrospectively on a time scale between $2^{\text {nd }}$ of April 2019 till $30^{\text {th }}$ of October 2019. Items of data set consist of the following list

1. Hashtags

2. Name of account

3. Media data

4. Message inside the picture or video

5. Number of Likes on tweet

6. Number of Comments

7. Number of Retweets

8. Comments on related tweets

9. Time of tweet published

10. Date of tweets Published

11. Type of user account

12. Mobilizing information related to accounts

13. User city

14. User country

15. Tweet link

16. User Link

17. Followers

18. Following

19. Joining date of user

Incomplete data was excluded in the data file. The present study does not need an ethical approval as there is no participant were involved in the study and the data is publically available on twitter. All the available data are in accordance to European Commission guidelines on FAIR Data Management in Horizon 2020 (10)(11). The Checklist is provided inside the 
appendix- A. The data will be useful to researchers for sentimental analysis and qualitative analysis of tweet to determine the effectiveness of campaign.

\section{Data availability}

Underlying data

Open Science Framework: A Retrospective dataset on Climate Strike Twitter Hashtags; registration DOI 10.17605/OSF.IO/EGSQY.

This project contains the following underlying data:

- Climate strike.xlsx. (The dataset.)

- Items of dataset.txt.

Data are available under the terms of the Creative Commons Zero "No rights reserved" data waiver (CC0 1.0 Public domain dedication).

\section{Funding}

This work was supported by the Research Management Center, Xiamen University Malaysia, grant number XMUMRF/2020-C6/ITCM/0005. The funding body had no role in the design and conduct of this study; the collection, management, analysis, and interpretation of the data; the preparation, review, and approval of the manuscript; or the decision to submit the manuscript for publication.

\section{Acknowledgments}

This research was supported by Xiamen University Malaysia. The funders had no role in study design, data collection and analysis, decision to publish, or preparation of the manuscript.

\section{Author contributions}

Muhammad Shahzad Aslam, Yun Jin Kim, Linchao Qian authored the data note, designed and carried out the research. Sana Saeed recorded the data collection.

\section{Competing interests}

No competing interest found during this study

\section{Grant information}


The author(s) declared that no grants were involved in supporting this work.

\section{ORCID ids}

Sana Saeed https://orcid.org/0000-0001-6011-5844

Yun Jin Kim https://orcid.org/0000-0001-8853-6587

Linchao Qian https://orcid.org/0000-0002-4825-0725

Muhammad Shahzad Aslam https://orcid.org/0000-0003-2728-6726

\section{References}

1. Crowley RA. Climate Change and Health: A Position Paper of the American College of Physicians. Ann Intern Med [Internet]. 2016 May 3;164(9):608. Available from: http://annals.org/article.aspx?doi=10.7326/M15-2766

2. Mirsaeidi M, Motahari H, Taghizadeh Khamesi M, Sharifi A, Campos M, Schraufnagel DE. Climate Change and Respiratory Infections. Ann Am Thorac Soc [Internet]. 2016 Aug;13(8):1223-30. Available from: http://www.atsjournals.org/doi/10.1513/AnnalsATS.201511-729PS

3. Glaser J, Lemery J, Rajagopalan B, Diaz HF, García-Trabanino R, Taduri G, et al. Climate Change and the Emergent Epidemic of CKD from Heat Stress in Rural Communities: The Case for Heat Stress Nephropathy. Clin J Am Soc Nephrol [Internet]. 2016 Aug 8;11(8):1472-83. Available from: https://cjasn.asnjournals.org/lookup/doi/10.2215/CJN.13841215

4. Boulianne S, Lalancette M, Ilkiw D. "School Strike 4 Climate": Social Media and the International Youth Protest on Climate Change. Media Commun [Internet]. 2020 May 19;8(2):208-18. Available from:

https://www.cogitatiopress.com/mediaandcommunication/article/view/2768

5. Taylor M, Watts J, Bartlett J. Climate crisis: 6 million people join latest wave of global protests. The Guardian. 2019;

6. Anger I, Kittl C. Measuring influence on Twitter. In: Proceedings of the 11th International Conference on Knowledge Management and Knowledge Technologies i-KNOW'11 [Internet]. New York, New York, USA: ACM Press; 2011. p. 1. Available from: http://dl.acm.org/citation.cfm?doid=2024288.2024326

7. Lin Y. 10 Twitter Statistics Every Marketer Should Know in 2020 [Infographic] [Internet]. [cited 2020 Dec 13]. Available from: https://my.oberlo.com/blog/twitterstatistics

8. Chung JE. A Smoking Cessation Campaign on Twitter: Understanding the Use of 
Twitter and Identifying Major Players in a Health Campaign. J Health Commun [Internet]. 2016 May 3;21(5):517-26. Available from:

http://www.tandfonline.com/doi/full/10.1080/10810730.2015.1103332

9. Lawrence RG, Molyneux L, Coddington M, Holton A. Tweeting Conventions. Journal Stud [Internet]. 2014 Nov 2;15(6):789-806. Available from:

http://www.tandfonline.com/doi/abs/10.1080/1461670X.2013.836378

10. European Commission Directorate-General for Research \& Innovation. H2020 Programme Guidelines to the Rules on Open Access to Scientific Publications and Open Access to Research Data in Horizon 2020. Eur Comm. 2017;

11. Commission E. H2020 Programme Guidelines on FAIR Data Management in Horizon 2020. 2016. 